MODELING, IDENTIFICATION AND CONTROL, 2001, VOL. 22, NO. 4, 201-210

doi:10.4173/mic.2001.4.1

\title{
Modelling and Simulation of Variable Speed Thruster Drives with Full- Scale Verification
}

\author{
JAN FREDRIK HANSEN, TRYGVE LAUVDAL, ALF KÅRE \\ ÅDNANES
}

Keywords: Marine systems, modelling, simulation, verification, electrical machines, drives

\begin{abstract}
In this paper considerations about modelling and simulation of variable speed thruster drives are made with comparison to full scale measurements from Varg FPSO. For special purpose vessels with electric propulsion operating in DP (Dynamic Positioning) mode the thruster drives are essential for the vessel operation. Different model strategies of thruster drives are discussed. An advanced thruster drive model with a dynamic motor model and field vector control principle is shown. Simulations are performed with both the advanced model and a simplified model. These are compared with full-scale measurements from Varg FPSO. The simulation results correspond well with the measurements, for both the simplified model and the advanced model.
\end{abstract}

\section{Introduction}

Electric propulsion systems are found to be beneficial in several ship applications with a varying velocity profile, such as supply vessels, floating production vessels, drill-ships, shuttle-tankers, ice-breakers, naval ships and cruise liners. Description of different kind of configurations, applications, maintenance, safety and class rules and regulations can be found in (IMarE, 1995), (IMarE, 1998), (NIF, 1996) and (NIF, 1998).

The basic idea with such systems is to replace the main diesel propulsion engines with electric motors, and split the power production into several smaller dieselgenerators, and then for every load demand choose the optimal number of generators. The advantages are improved efficiency for operation below full load operation (which may be up to $90 \%$ of time for some type of vessels), improved availability due to redundancy improvement by the power system arrangement, better maneuverability by using azimuthing/podded propulsion, higher flexibility with engine room arrangement, and simplified maintenance by optimal running of diesel generators. On the other side electric propulsion means more components and higher investment costs, and additional losses in full load operation. In (Hopkins, 1991), (Hill et al., 1992) and (Schriek and de Nijs, 1991) descriptions of systems and strategies implemented on actual ships are given.

For vessels operating in DP (Dynamic Positioning) or PM (Positioning Mooring) the variable speed thruster drives are essential for successful operation. These may be of different kinds as large synchronous motors driven either by Cycloconverters or Load Commutated Inverters (LCI) for large propulsion power and asynchronous motors driven by Pulse Width Modulated (PWM) converters for smaller thruster drives, see also (Ådnanes et al., 1997).

ABB Industri AS, P.O. Box 6540 Rodeløkka, N-0501 Oslo, Norway. Corresponding author: Jan Fredrik Hansen, tel: +47 228726 27, fax: +47 223536 80. e-mail: janfredrik.hansen@no.abb.com, trygve.lauvdal@no.abb.com, alf-kare.adnanes@̄no.abb.com 
Thruster drive models may be used as part of larger integrated vessel-simulators, including both power systems and vessel movements. These may be used for design purpose, fuel optimization, investigating new control technologies etc. For such simulators, simplified models may be used in order to speed up simulation time (neglecting fast dynamics), however describing the mechanical quantities and electrical power demand accurately. For more detailed investigation of thruster-drive performances more detailed models may be used. In this paper modelling and simulation of variable speed thruster drives is done. Different kind of modelling level is discussed comparing full dynamic models of electrical motors and propellers with simplified models where fast electrical dynamics are neglected. Simulations of the different models are compared and verified with full-scale measurements from Varg FPSO.

Outline of the paper: Modelling and control strategies are presented in Section 2. In Section 3 simulation results are compared with full-scale measurements. Finally in Section 4 some concluding remarks are drawn.

\section{Modelling and PWM control strategies}

There are several arrangements to be used in electrical thruster drives. Using variable pitch propellers the power and thrust force can be controlled by adjusting the pitch. For such systems the thruster motor may rotate at constant speed as for a Direct On Line (DOL) electrical motor or as for the conventional diesel propulsion. However the ever increasing development of electrical frequency converters utilize the variable speed and mechanical simplicity of fixed pitch solution. Using this configuration, torque, speed and power can be controlled accurately both static and dynamic.

For electrical thruster drives with power rating less than approximated 5-7MW the asynchronous motors with Pulse Width Modulated (PWM) converters are dominating. These are considered further in this paper.

\subsection{Advanced models}

\section{Fixed pitch propellers (mechanical states):}

The fixed pitch propellers are modelled as in Fossen (1994). The model calculates the mechanical torque of the propeller as a function of propeller speed:

$$
T_{m}=\rho D^{5} K_{Q} n|n|
$$

where $\rho$ is sea-water density, $D$ is propeller diameter, $K_{Q}$ is propeller torque coefficient, and $n$ is propeller speed in rps. The mechanical state equation is then:

$$
\dot{n}=\frac{1}{2 \pi J}\left(T_{e}-T_{m}\right)
$$

where $J$ is moment of inertia for both propeller, shaftline and electrical motor and $T_{e}$ is electrical torque in $\mathrm{Nm}$.

\section{Asynchronous motor (electrical states):}

A dynamic two-axis $(d q)$ model describing the asynchronous motor is given in $p u$ as (Bühler, 1977):

$$
u_{d s}=r_{s} i_{d s}+\frac{1}{\omega_{n}} \frac{d \psi_{d s}}{d t}-f_{s} \psi_{q s}
$$




$$
\begin{gathered}
u_{q s}=r_{s} i_{q s}+\frac{1}{\omega_{n}} \frac{d \psi_{q s}}{d t}+f_{s} \psi_{d s} \\
0=r_{r} i_{d r}+\frac{1}{\omega_{n}} \frac{d \psi_{d r}}{d t}-f_{r} \psi_{q r} \\
0=r_{r} i_{q r}+\frac{1}{\omega_{n}} \frac{d \psi_{q r}}{d t}+f_{r} \psi_{d r}
\end{gathered}
$$

where:

$$
\begin{aligned}
& \psi_{d s}=x_{s} i_{d s}+x_{h} i_{d r} \\
& \psi_{q s}=x_{s} i_{q s}+x_{h} i_{q r} \\
& \psi_{d r}=x_{r} i_{d r}+x_{h} i_{d s} \\
& \psi_{q r}=x_{r} i_{q r}+x_{h} i_{q s} \\
& f_{r}=f_{s}-\Omega
\end{aligned}
$$

where $\psi$ is flux-linkage, $i$ is current, $u$ is voltage, $f$ is frequency, $\Omega$ is mechanical speed and $\omega_{n}$ is nominal angular velocity. Subscripts $d$ and $q$ denotes $d$-axis and $q$-axis respectively and $s$ and $r$ denotes stator and rotor respectively. All equations are given in $p u$ such that $f_{s}$ equals $\Omega$ when motor has synchronous speed.

Using compact vector form (3) and (4) can be written as followed: Define vectors: $\psi=\left[\psi_{d s}, \psi_{q s}, \psi_{d r}, \psi_{q r}\right]^{T}, \mathbf{i}=\left[i_{d s}, i_{q s}, i_{d r}, i_{q r}\right]^{T}, \mathbf{u}=\left[u_{d s}, u_{q s}\right]^{T}$, then:

$$
\begin{aligned}
\dot{\psi} & =\omega_{n}(\mathbf{F} \psi+\mathbf{R i}+\mathbf{B u}) \\
\psi & =\mathbf{X i} \\
& \downarrow \\
\dot{\psi} & =\omega_{n}\left(\mathbf{F}+\mathbf{R} \mathbf{X}^{-1}\right) \psi+\omega_{n} \mathbf{B u}
\end{aligned}
$$

where: $\mathbf{R}=\operatorname{diag}\left\{r_{s}, r_{s}, r_{r}, r_{r}\right\}$

$$
\begin{aligned}
\mathbf{F} & =\left[\begin{array}{cccc}
0 & f_{s} & 0 & 0 \\
-f_{s} & 0 & 0 & 0 \\
0 & 0 & 0 & f_{r} \\
0 & 0 & -f_{r} & 0
\end{array}\right], \mathbf{B}=\left[\begin{array}{ll}
1 & 0 \\
0 & 1 \\
0 & 0 \\
0 & 0
\end{array}\right] \\
X & =\left[\begin{array}{cccc}
x_{s} & 0 & x_{h} & 0 \\
0 & x_{s} & 0 & x_{h} \\
x_{h} & 0 & x_{r} & 0 \\
0 & x_{h} & 0 & x_{r}
\end{array}\right]
\end{aligned}
$$


The torque equation is:

$$
t_{e}=\psi_{d s} i_{q s}-\psi_{q s} i_{d s}=\frac{x_{h}}{x_{r}}\left(\psi_{d r} i_{q s}-\psi_{q r} i_{d s}\right)
$$

\section{Pulse Width Modulated (PWM) converter:}

The model of a PWM converter contains two parts, a power model and a control model. The power model part calculates the active and reactive power demand from the switchboard. The active power demand will be the asynchronous motor power demand with converter losses added. The converter operates at an efficiency of above $99 \%$ at rated load. The converter losses will be dominated by conducting losses, switching losses and auxiliary power demand. For a PWM converter with a diode bridge rectifier the power factor is greater than 0,95 for full load and rising to 1,0 for no load. This is used to calculate the reactive power demand. The controller part contains different low-level PI-controllers depending on selected control strategy. The PWM converter supplies the asynchronous motor with the desired voltage and frequency based on selected control strategy. The field-vector control principle was first introduced by Hasse (1969) and Blaschke (1972). Several other publications also describe the field-vector control principle in different ways. In this paper the description of vector control of induction machines described in Nicklasson (1996) is followed. The field vector control principle is to control both torque and flux independently as for a DC motor. However for the asynchronous squirrel cage motor only the stator winding is available for control action. The field vector principle is then to control the voltage and the frequency of the stator winding in such a way that torque and flux can be controlled separately. To achieve the best decoupling and dynamic performance of the torque the rotor flux should be kept at rated value for all operation levels. From equation (8) it is seen that if $\psi_{q r}=0$, then $\psi_{\mathrm{dr}}=c$ where $c$ is a positive constant the torque output would be proportional to $i_{q s}$. Also from (3) and (4) with $\psi_{q r}=0$ :

$$
\dot{\psi}_{d r}+\frac{\omega_{n} r_{r}}{x_{r}} \psi_{d r}=r_{r} \frac{x_{h}}{x_{r}} i_{d s}
$$

Hence $\psi_{d r}$ can be controlled by $i_{d s}$. The remaining problem is then to control $i_{d s}$ and $i_{q s}$. The flux decoupling can be achieved with a nonlinear dynamic decoupler for perfect cancellation of parts of dynamics in (7) to secure $\psi_{q r}=0$ or a high gain controller can be used for simplicity. Figure 1 shows how the field vector control principle is implemented in this paper, and not how it is implemented on actual PWM converters. This is a simplified version using nested PI-controllers, and assumed adequate for the purpose of this paper. $\psi_{q r}$ is controlled by $u_{q} . i_{q s}\left(\right.$ or $\left.t_{e}\right)$ is controlled by the frequency and $i_{d s}$ is controlled by the voltage $u_{d}$. The speed is controlled by an outer PI-control loop manipulating $i_{q r e f}$ as the reference for the torque controller.

\section{Thruster transformers:}

The variable speed thruster drives may be supplied by thruster transformers. If a low harmonic distortion level is needed on the main switchboard, three-winding transformers are used for 12-pulse configuration. If 6-pulse configuration is acceptable for harmonic distortion level, transformers may be omitted if the voltage level of the switchboard correspond with the converter voltage level. Also filters may be installed 


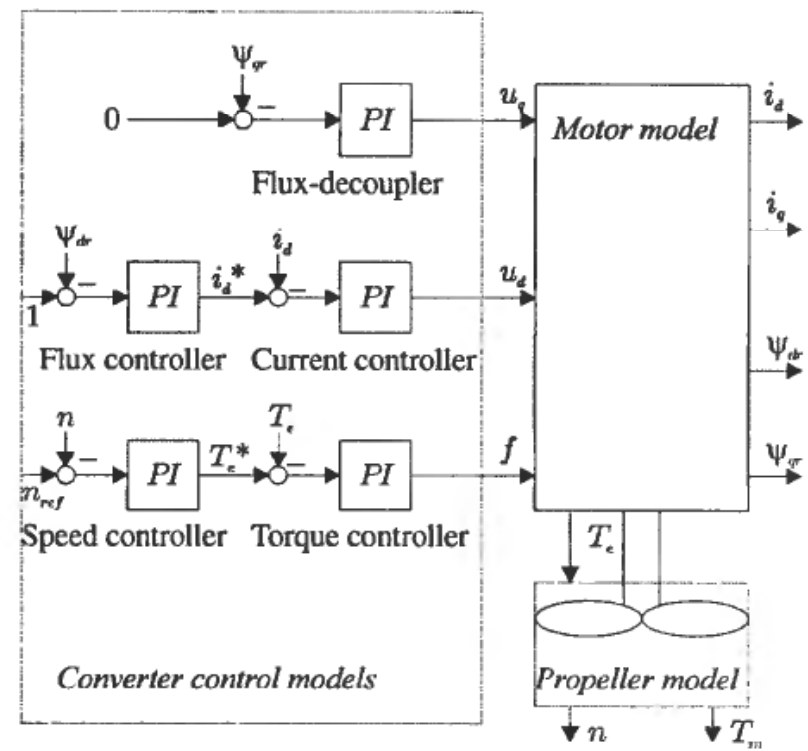

Figure 1. Block-diagram of modelled vector control strategy.

to reduce the harmonic distortion level. The efficiency of transformers is above $99 \%$ at rated load.

\subsection{Simplified models}

In order to include the thruster drive models in a larger simulation package as a part of a total marine power system where the main purpose is to predict thrust force, propeller RPM, and electrical power demand, some simplifications may be done to speed up simulation time. This can be done by neglecting all the electrical dynamics while keeping the mechanical dynamics, and computing the electrical power quantities by algebraic equations. A reasonable approximation in this sense is to look at the converter and the asynchronous motor in one scope.

The RPM reference signal for the thruster drive is given by a supervisory vessel controller (e.g Dynamic Positioning controller). The local RPM controller in the converter then controls the torque setpoint for the torque controller (also inside the converter). For the simplified models the torque response of the motor is assumed to be very fast $(<50 \mathrm{~ms})$ compared to the mechanical time constant in the shaft-line (in seconds), the torque response is assumed to be instant for the simplified models.

The total system is then assumed to consist of the propeller equations (1), (2) and a RPM controller manipulating $T_{e}$ in (2) directly. The electrical power demand (active and reactive) is computed by algebraic equations based on the equivalent circuit diagram of a typical asynchronous motor and the PWM power model as described in the previous section.

\section{Simulations and Verifications}

In this section simualtions for both the advanced models and the simplified models are compared with full-scale measurements from Varg FPSO (Floating Production Storage and Off-loading vessel). The measurements were taken during 


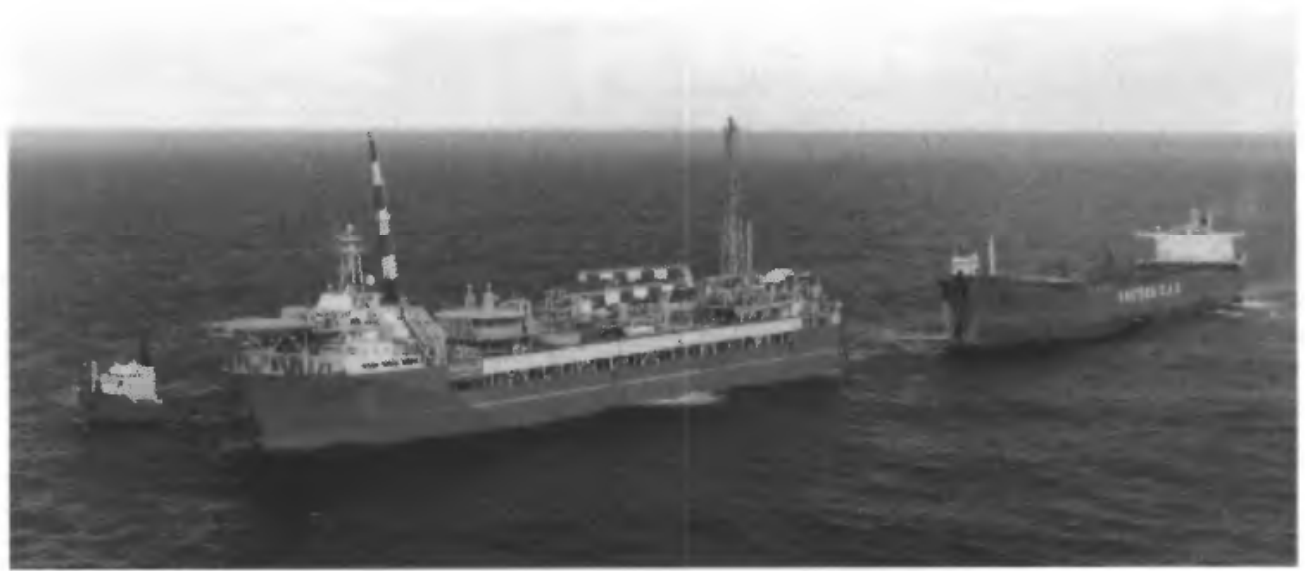

Figure 2. Varg FPSO at operation in the North-Sea during offloading to shuttle tanker.

sea-trials and while operating as production vessel in the North-Sea. All simulations are performed in Matlab.

\subsection{Case description}

Figure 2 shows Varg at operation in the North-Sea. The power system of Varg consists of $11 \mathrm{kV}$ Switchboards, 5 generators, 3 variable speed thruster drives and several DOL (Direct On Line) motors. Total innstalled power is about $40 \mathrm{MW}$ while the thruster drives are $3 \times 2,8 \mathrm{MW}, 12$-pulse configuration. Maximum RPM for the thruster motors is 1000 . Note that there is a gear between the motor and the propeller so that the propeller RPM is considerably lower, but all the measurements are taken from the motor shaftline, hence all the following simulation and measurements plots are refered to this shaftline. The RPM references for the simulations are taken from the logged RPM references from the DP-controller.

\subsection{Full dynamic models}

Simulations using the advanced motor model given in (7) are shown in Figure 3 for a long term simulation of 1000 s. A more detailed plot of the first 140 s is shown in Figure 4 and the corresponding thruster power is shown in Figure 5. The vector control strategy as explained in the previous section is used. For the thruster RPM and Power the simulations are compared to full-scale measurements from Varg FPSO. Only mechanical thruster power were available for the measurements. The simulated electrical power is included for illustration and to show the electrical losses in the asynchronous motor. The logged data from the measurements may contain different time delays in the same sequence, such that some of the vertical differences between the simulations and the measurements may be explained by that. Otherwise the tuning of the controllers will of course affect the results very much, especially the RPM controller.

The inner control loops (torque, flux and current controllers) are tuned with a high gain as possible in order to get as fast torque responese as possible and keep the flux magnitude as close to rated value as possible for the different load conditions. 


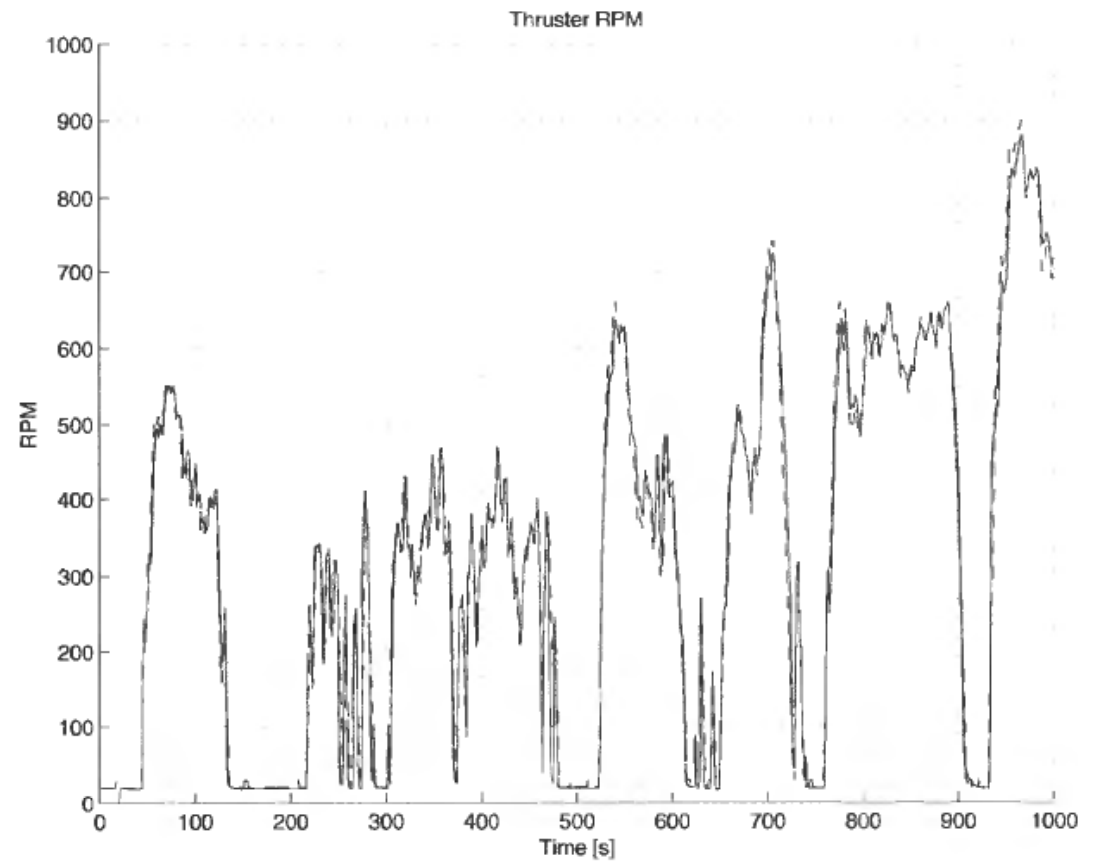

Figure 3. Thruster RPM, advanced model simulation (-) compared with measurements (- -).

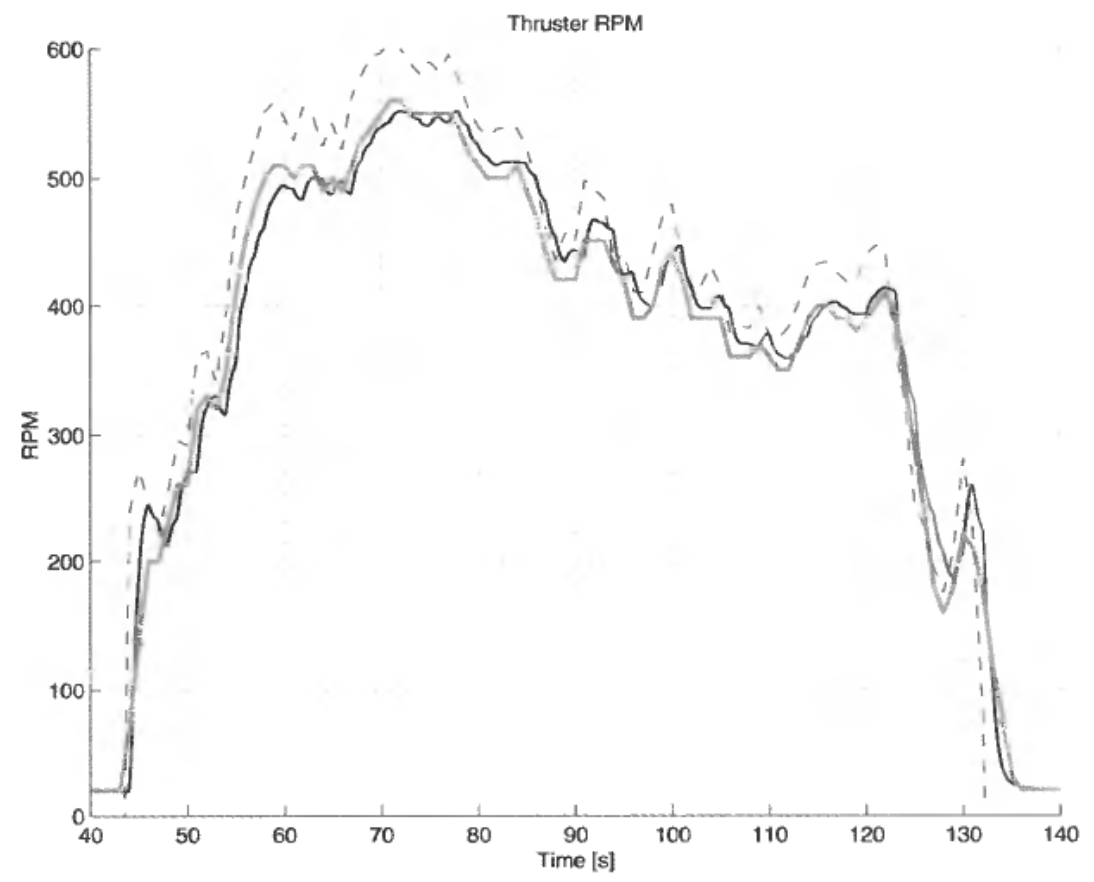

Figure 4. Thruster RPM for simulated and measured values with advanced simulation models Simulation (black), measurement (grey) and reference (--). 


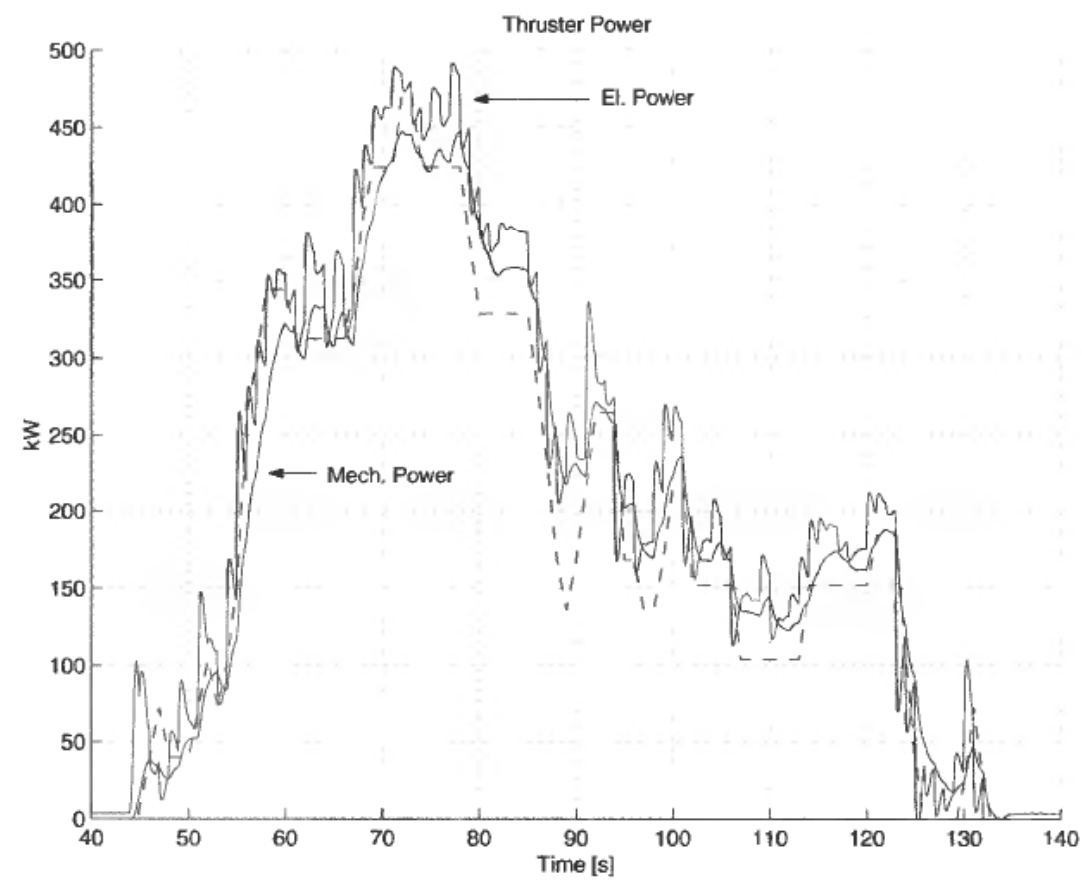

Figure 5. Thruster power for simulated (mechanical and electrical) and measured (mechanical) values with advanced simulation models. Simulation (-), measurements (--).

\subsection{Simplified models}

Simulations with the simplified models are compared with the same measurements as for the advanced model simulation. These are shown in Figures 6 and 7. Also for this system the tuning of the RPM controller affects the results, however in this case the RPM controller is the only controller to tune and this simplifies the simulation. Also due to the simplified models the simulation time is reduced considerably.

\section{Concluding remarks}

Modelling and simulation of variable speed thruster drives is done and verified with full-scale measurements from the sea-trials of Varg FPSO. A full dynamic model of an asynchronous motor is presented with a brief explanation of the field vector control principle. Also a simplified simulation model for the thruster drive is suggested which treats the motor and converter as an unified system giving the desired torque commanded from the RPM-controller.

The performance of the simulation results are very good compared with the measurements, for both the advanced and the simplified model, in fact there seems to be even better similarity between the simple model simulations and the measurements. This is due to the simpler configuration of controllers, with only the RPM controller to tune for the simplified model. Another aspect is that the measurements do not capture all dynamics with the accuracy required to fully verify the advanced model dynamics.

This shows that the simplified models are sufficient for giving a good indication on how the RPM and power consumption of the thruster drives are varying. On the 


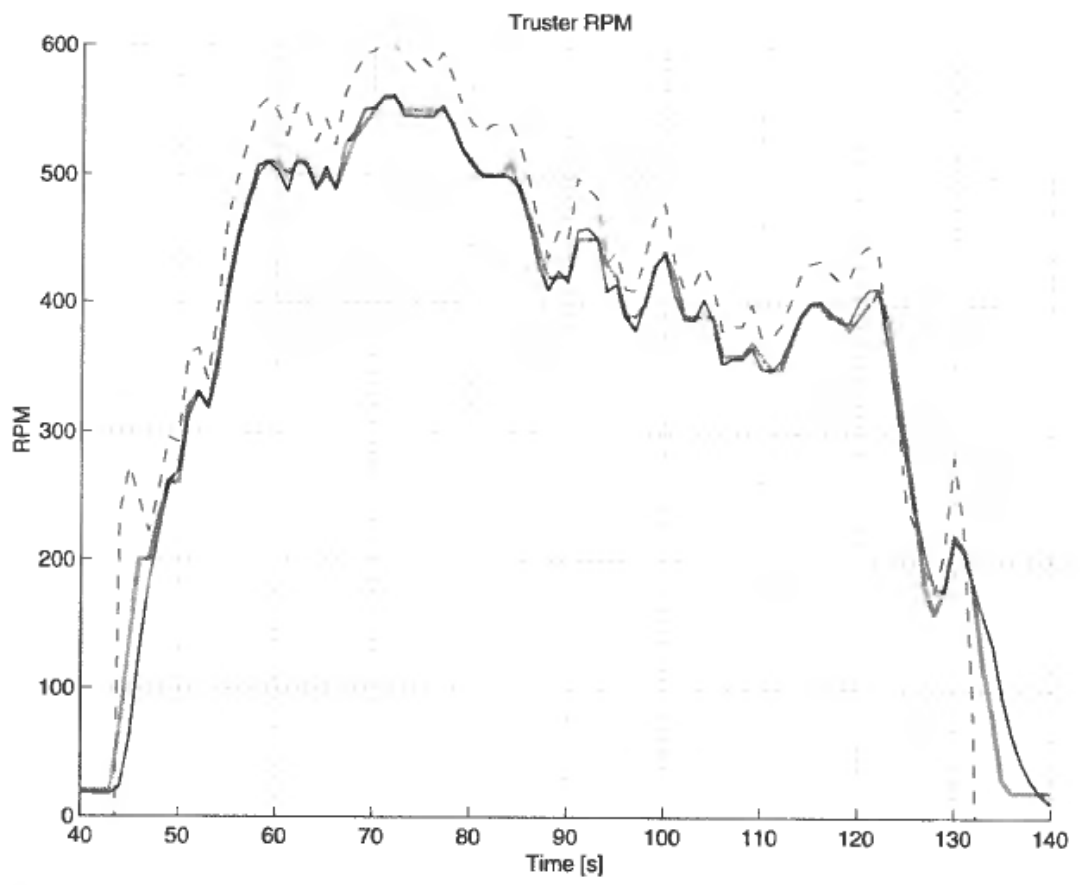

Figure 6. Thruster RPM for simulated and measured values with simplified simulation models. Simulation (black), measurement (grey) and reference (--).

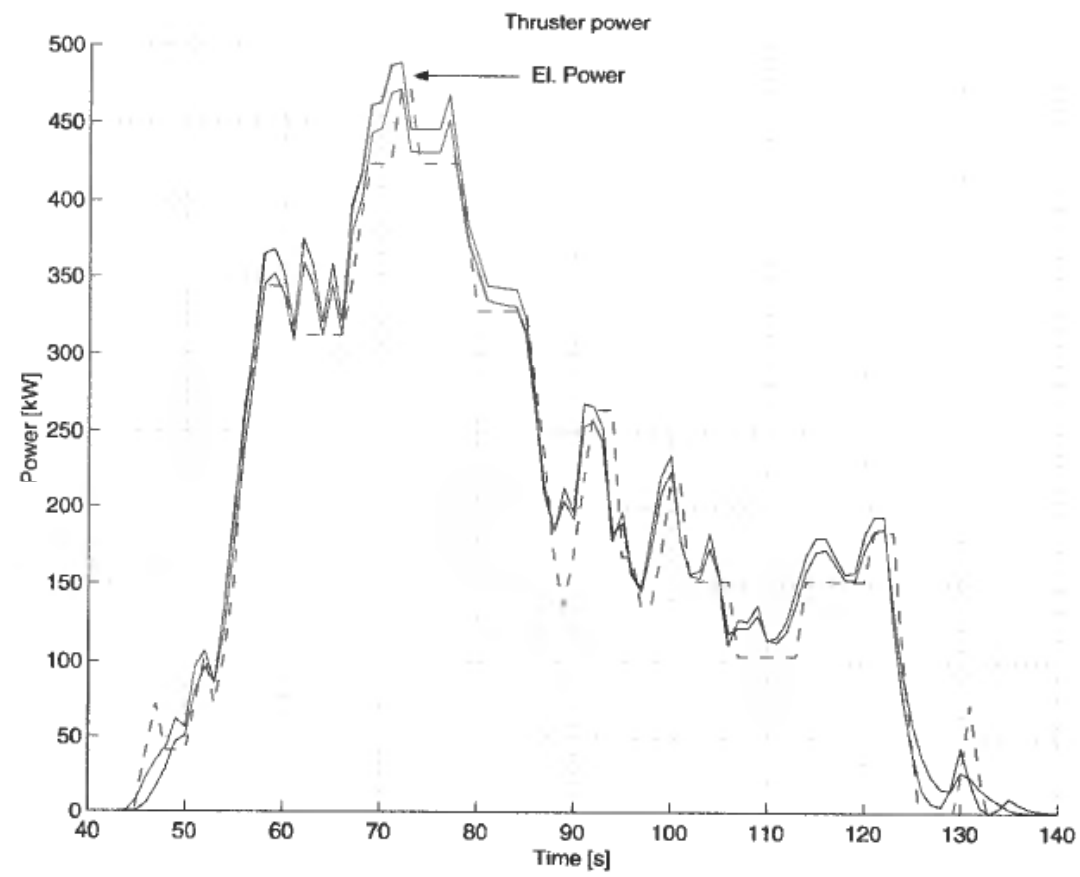

Figure 7. Thruster power for simulated (mechanical and electrical) and measured (mechanical) values with simplified simulation models. Simulation (-), measurement (--). 
other side the simple model would not be suitable for advanced dynamic performance studies of large transients etc. Another aspect for the advanced models is that the motor parameters (both resistances and inductances) is needed to be known accurately. For the simplified model mainly the resistances are needed to compute the power losses. The inductances could be given more roughly in order to estimate the reactive power demandand hence the magnitude of the motor current.

For a larger simulation tool integrating vessel simulation with the power system the simplified models would be very suitable, not at least with respect to simulation time.

\section{REFERENCES}

Ådnanes, A. K., Sørensen, A. J. and Hackman, T. (1997). Essential characteristics of electrical propulsion and thruster drives in DP vessels. In: Dynamic Positioning Conference, DPC'97. Houston, Texas.

BLASCHKE, F. (1972). The principle of field orientation as applied to the new TRANSVEKTOR closed-loop control system for rotating field machines. Siemans Review XXXIX (5), 217-220.

BüHLER, H. (1977). Einführung in Die Theorie Geregelter Drehstrom-Antriebe. Birkhäuser Verlag Basel.

FossEn, T. I. (1994). Guidance and Control of Ocean Vehicles. John Wiley \& Sons.

HASSE, K. (1969), Zur Dynamik Drehzahlgeregelter Antriebe-Kurzschlussläfermaschinen. PhD thesis. Techniscen Hochschule Darmstadt (in German).

Hill, W. A., Creflman, G. and MisschKe, L. (1992). Control strategy for an icebreaker propulsion system. IEEE Transactions on industry applications 28(4), 887-892.

HopkINS, J. W. (1991). Fantasy and reality. Trans IMarE 103, 193-220.

IMArE, Ed. (1995). Electric Propulsion, The Effective Solution? The Institute of Marine Engineers.

IMARE, Ed. (1998). All Electric Ship, Eveloping Benefits for Maritime Applications. The Institute of Marine Engineers.

Nicklasson, P. J. (1996). Passivity-Based Control of Electric Machines. PhD thesis. Norwegian University of Science and Technology.

NIF, Ed. (1996). 1st International Conference on Diesel Electric Propulsion - a Cost Effective Solution. Norwegian Society of Chartered Engineers.

SCHRIEK, D. and DE NIJS, (1991). Royal netherlands navy m class frigate: Integrated monitoring and control system and electrical installation. Trans IMarE 103, 269-291. 